\title{
Anterior Positioning Screw in Proximal Femoral Plating Restricts Posterior Tilt of Retroverted Femoral Neck Fractures: a Retrospective Cohort Study
}

Sheng-Bo Nie

Shanghai Tenth People's Hospital

Jun-Feng Liu

Shanghai Tenth People's Hospital

Jiang-Hua Zhu

Shanghai Tenth People's Hospital

Zi-Fei Zhou

Shanghai Tenth People's Hospital

Lei Zhang

Shanghai Tenth People's Hospital

Long-Po Zheng ( $\nabla$ dr.zheng@tongji.edu.cn )

Shanghai Tenth People's Hospital https://orcid.org/0000-0002-1749-2449

\section{Research Article}

Keywords: Femoral neck fractures, Proximal femoral plating, Posterior tilt, Femoral neck shortening, Positioning screw

Posted Date: March 10th, 2021

DOI: https://doi.org/10.21203/rs.3.rs-282853/v1

License: (c) (i) This work is licensed under a Creative Commons Attribution 4.0 International License. Read Full License 


\section{Abstract}

Background: Preoperative posterior tilt is a risk factor for fixation failure in femoral neck fractures. This study aimed to evaluate the configuration of anterior positioning screw in proximal femoral plating in the treatment of retroverted femoral neck fractures in terms of resisting posterior tilt.

Methods: We retrospectively analyzed patients with retroverted femoral neck fractures who were fixed by proximal femoral plating from January 2014 to August 2019. All patients were divided into two groups according to screw configuration: anterior long-threaded screw (ALTS, $n=36$ ) and normally shortthreaded screws (NTS, $n=46$ ). Baseline characteristics were reviewed and radiological and clinical outcomes were analyzed. Logistic regression analysis was used to identify risk factors for developing posterior tilt.

Results: Demographic data showed no significant difference. Increased posterior tilt was lower in the ALTS group $\left(3.2^{\circ}, 2.1-4.3^{\circ}\right)$ than that in the NTS group $\left(5.3^{\circ}, 4.2-8.3^{\circ}\right)(p<0.001)$, and the percentage of people with $>5^{\circ}$ of posterior tilt was also lower in the ALTS group (5, 13.9\% vs. 24, 52.2\%; $\left.p<0.001\right)$. Femoral neck shortening (FNS) was lower in the ALTS group (3.1 (2.1 - 4.7) mm vs. $4.3(3.1-6.3) \mathrm{mm}, \mathrm{p}$ $=0.003)$, though not statistically significant when using $5 \mathrm{~mm}$ as the cut-off value. Harris Hip Score in the ALTS group was higher than that in the NTS group (87.0, $84.0-90.0$ vs. 82.0, $76.0-84.5 ; p<0.001$ ). Postoperative complications including delayed union, nonunion, and avascular necrosis were comparable between the groups. Multivariable analysis identified posterior comminution (OR 15.9, 95\% $\mathrm{Cl} 3.6-70.3$, $\mathrm{p}<0.001)$, suboptimal reduction quality $(\mathrm{OR} 12.0,95 \% \mathrm{Cl} 2.6-56.1, \mathrm{p}=0.002)$, and NTS configuration (ref: ALTS configuration) (OR 21.9, 95\% $\mathrm{Cl} 4.1-116.4, \mathrm{p}<0.001$ ) as risk factors for developing posterior tilt.

Conclusions: Configuration of anterior positioning screw in proximal femoral plating provides better resistance against posterior tilt in the fixation of retroverted femoral neck fractures. Also, posterior comminution, suboptimal reduction, and NTS configuration (ref: ALTS) are risk factors for developing posterior tilt.

Trial registration: Retrospectively registered.

\section{Background}

The prevalence of femoral neck fractures increases with the aging population and is a serious healthcare problem worldwide due to high morbidity and mortality rates [1, 2]. In internal fixation of femoral neck fractures, fixation failure is not uncommon, and no consensus has been reached regarding the optimal fixation construct. Preoperative posterior tilt (or retroversion) of the femoral head has been recognized as an important risk factor for fixation failure of femoral neck fractures [3-5]. Since retroversion of the femoral head would largely cause damage of the posterior cortex and/or weaken the osseous mechanical transduction, the fracture would still present with posterior instability even after anatomic reduction. If the inclination of posterior tilt is not antagonized, the femoral head would largely develop 
retroversion after seemingly "good" fixation. Thus, more specific fixation construct is need in treating retroverted femoral neck fractures.

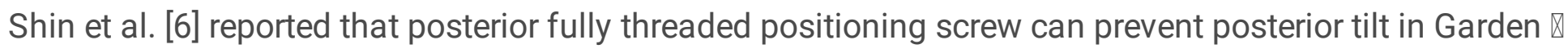
and $\triangle$ femoral neck fractures; Zhang et al. [7] reported that inferior two fully threaded compression screws (functions as positioning screws after fixation) can decrease varus deformity and fixation failure in vertical femoral neck fractures. However, in retroverted femoral neck fractures, no such hybrid screw construct has been reported, and whether using an anterior positioning screw in a plating construct can resist posterior tilt of retroverted femoral neck fractures remains unknown.

In this study, we retrospectively analyzed the novel configuration of anterior long-threaded positioning screw in proximal femoral plating for the fixation of retroverted femoral neck fractures, and evaluated its effect in resisting posterior tilt and neck shortening. Additionally, risk factors for developing posterior tilt of femoral head were also identified using multivariable analysis.

\section{Methods}

\section{Study design and patient selection}

The requirement for informed consent from the patients was waived due to the retrospective nature of this study, and this study was approved by the ethics committee of our hospital. The inclusion criteria were as follows: (1) femoral neck fractures with preoperative posterior tilt, (2) closed reduction and proximal femoral plate fixation (anterior long-threaded cannulated screw (ALTS) configuration or normally short-threaded cannulated screws (NTS) configuration), and (3) a minimum follow-up of 12 months. The exclusion criteria were more than $10^{\circ}$ of remaining posterior tilt after reduction, pathological fractures, malignancies, hip arthritis, or lost to follow-up. Finally, a total of 82 patients were included in this study (ALTS, $n=36$; NTS, $n=46$ ). The medical records were reviewed and baseline characteristics were compared between the two groups.

\section{Fracture management}

The patient received general anesthesia and was placed in supine position. Fracture reduction was conducted by imposing manual pressure on the anterior part of femoral head assisted with manipulation of the lower extremity. K-wire that inserted to the femoral head was used for reduction when necessary. After achieving satisfactory reduction, the plate was placed and three inverted guide pins were inserted through the plate holes in the configuration of inferior-center, superior-anterior, and superior-posterior. Then, in the ALTS group, a long-threaded cannulated screw was inserted superior-anteriorly to function as a positioning screw, and then, two short-threaded screws were inserted along the guide pins and rational compression force was imposed to achieve bone contact at the fracture site. In the NTS group, instead, three short-threaded screws were inserted in sequence along the guide pins and compression force was imposed to achieve instant compression at the fracture site. The plate was finally fixed to the femoral 
shaft with a distal screw. None-weight-bearing exercise was prescribed to the patients instantly after surgery.

\section{Clinical and radiological outcome measurement}

Medical records and radiographs were reviewed for the following data: age, gender, Garden type, posterior comminution and reduction quality. Smooth contact of the medial cortex was defined as excellent reduction, translation of less than one cortex was defined as good, while more than one cortex thickness of residual translation was regarded as moderate/poor. The caput-collum-diaphysis (CCD) angle was measured as described by Park et al. [8]. Briefly, a line from the center of the femoral head to the center of the femoral neck constitutes the femoral neck axis. The angle between the femoral neck axis and the bisecting line of the femoral shaft constitutes the CCD angle (Fig. 3). The amount of femoral neck shortening (FNS) was measured on AP radiographs as described by Zlowodzki et al. [9]. In short, the contour of the unaffected side was overlapped on the contour of the injured side. Changes in the $x$-axis and y-axis were measured. The amount of FNS was calculated using $\theta$ as the corresponding CCD angle as follows: $z=y \cdot \sin (\theta)+x \cdot \cos (\theta)$, as was described by Weil et al. [10]. Decreased CCD angle was calculated by comparing CCD angle measured at 12 months postoperatively with that of the unaffected side measured before surgery. Posterior tilt was measured using the method as described in the literature $[11,12]$. Nonunion was defined as a clear fracture line on the X-ray at follow-up of six months [13]. Harris Hip Score (HHS) was assessed at follow-up of 12 months.

\section{Statistical analysis}

For continuous data, normality was tested using the Kolmogorov-Smirnov test. Normally distributed continuous data were presented as mean \pm standard deviation (SD), while median and interquartile range were presented for non-normally distributed continuous data. Categorical variables were presented as frequencies or percentages. Independent sample $t$ test was used to compare normally distributed continuous data; otherwise, non-parametric test was conducted. Chi-square test was performed for categorical variables. Statistical significance was defined as $p<0.05$. Univariate logistic regression was performed on each selected variable to determine differences between the two groups. Odds ratios were obtained with $95 \%$ confidence intervals. Variables with $p \leq 0.05$ were incorporated into the subsequent multivariate analysis. Statistical analyses were performed using IBM SPSS (version 22.0) and GraphPad Prism (version 8.0).

\section{Results}

The mean follow-up time was 14.0 (12.0-16.0) months for the ALTS group and 15.5 (12.8-16.0) months for the NTS group $(p=0.49)$. The two groups were comparable regarding age, gender, Garden type, posterior comminution, and reduction quality ( $p>0.05$, Table 1$)$. 
Table 1

Baseline characteristics and comparative analysis between the two groups

\begin{tabular}{|c|c|c|c|}
\hline Variables & ALTS $(n=36)$ & NTS $(n=46)$ & $p$ value \\
\hline Age (years) & $56.3 \pm 9.4$ & $54.6 \pm 7.6$ & 0.37 \\
\hline Gender (male/female) & $15 / 21$ & $23 / 23$ & 0.45 \\
\hline Garden type & & & 0.33 \\
\hline$\nabla / \nabla$ & 13 & 12 & \\
\hline$\nabla / \nabla$ & 23 & 34 & \\
\hline Posterior comminution & 13 & 18 & 0.78 \\
\hline Reduction quality & & & 0.95 \\
\hline Excellent/good & 24 & 31 & \\
\hline Moderate/poor & 12 & 15 & \\
\hline Increased posterior tilt $\left(^{\circ}\right)$ & $3.2(2.1-4.3)$ & $5.3(4.2-8.3)$ & $<0.001^{\star}$ \\
\hline Increased posterior tilt $\left(>5^{\circ}\right)$ & $5(13.9 \%)$ & $24(52.2 \%)$ & $<0.001^{*}$ \\
\hline Femoral neck shortening (mm) & $3.1(2.1-4.7)$ & $4.3(3.1-6.3)$ & $0.003^{*}$ \\
\hline Femoral neck shortening ( $>5 \mathrm{~mm})$ & 8 & 18 & 0.10 \\
\hline Decreased CCD angle $\left(^{\circ}\right)$ & $3.4(1.9-4.3)$ & $3.5(2.4-5.4)$ & 0.30 \\
\hline Harris Hip Score & $87.0(84.0-90.0)$ & $82.0(76.0-84.5)$ & $<0.001^{*}$ \\
\hline Delayed union & 6 & 7 & 0.86 \\
\hline Nonunion & 2 & 3 & 0.86 \\
\hline Avascular necrosis & 4 & 6 & 0.79 \\
\hline THA & 5 & 7 & 0.87 \\
\hline \multicolumn{4}{|c|}{ ALTS, anterior long-threaded cannulated screw; NTS, normally short-threaded cannulated screws. } \\
\hline * Statistically significant. & & & \\
\hline
\end{tabular}

\section{Radiological and clinical outcomes}

Figure 1 showed a representative case of retroverted femoral neck fracture fixed by proximal femoral plating using ALTS configuration. A long-threaded cannulated screw was inserted anteriorly (Fig. 1D). This patient achieved uneventful bone union six months postoperatively (Fig. 1H,I). Specifically, at follow- 
up of 12 months, barely any increased posterior tilt $\left(-3.3^{\circ}\right)$, decreased CCD angle $\left(3.8^{\circ}\right)$, or FNS $(2.6 \mathrm{~mm})$ was observed. The HHS at final follow-up was excellent.

Another representative case of retroverted femoral neck fracture treated with proximal femoral plating using NTS configuration was shown in Fig. 2. This patient achieved good reduction, while obvious posterior tilt occurred at follow-up of one month (Fig. 2E,F), and finally this patient developed malunion, with increased posterior tilt being $6.4^{\circ}$, FNS being $7.2 \mathrm{~mm}$, but with no significant varus deformity (decreased CCD angle: $-5.8^{\circ}$ ). The HHS was 76 and this patient received no further treatment due to endurable function.

In total, increased posterior tilt was lower in the ALTS group $\left(3.2^{\circ}, 2.1-4.3^{\circ}\right)$ than that in the NTS group $\left(5.3^{\circ}, 4.2-8.3^{\circ}\right)\left(p<0.001\right.$, Table 1, Fig. 4), and the percentage of people with $>5^{\circ}$ of posterior tilt was also lower in the ALTS group $(5,13.9 \%$ vs. $24,52.2 \%$; $<$ 0.001). FNS was lower in the ALTS group than that in the NTS group $(3.1,2.1-4.7 \mathrm{~mm}$ vs. $4.3,3.1-6.3 \mathrm{~mm} ; p=0.003)$, though when using $5 \mathrm{~mm}$ as the cut-off value, the difference showed no statistical significance $(p=0.10)$. Harris Hip Score in the ALTS group was higher than that in the NTS group (87.0, 84.0-90.0 vs. 82.0, 76.0-84.5; $p<0.001)$. Decreased CCD angle, delayed union, nonunion, avascular necrosis, and number of patients who converted to THA showed no significant difference $(p>0.05)$.

\section{Bivariate analysis of potential risk factors for developing posterior tilt $\left(>5^{\circ}\right)$}

To explore the potential risk factors for developing posterior tilt after surgery in retroverted femoral neck fractures, we reclassified all patients according to angle of increased posterior tilt with the cut-off value being $5^{\circ}$ (Table 2). Age, gender, Garden type, posterior comminution, fixation type, and reduction quality were compared. As a result, posterior comminution, NTS configuration (reference: ALTS configuration) and reduction quality showed significant difference $(p<0.05)$, which could be regarded as potential risk factors for developing posterior tilt. 
Table 2

Bivariate analysis of factors for developing posterior tilt $\left(>5^{\circ}\right)$

\begin{tabular}{|c|c|c|c|}
\hline Variables & $\begin{array}{l}\text { Increased posterior tilt }\left(\leq 5^{\circ}\right) \\
(n=53)\end{array}$ & $\begin{array}{l}\text { Increased posterior tilt }\left(>5^{\circ}\right) \\
(n=29)\end{array}$ & $p_{\text {value }}^{p}$ \\
\hline Age (years) & $55.3 \pm 8.2$ & $55.5 \pm 8.9$ & 0.94 \\
\hline Female gender & 28 & 16 & 0.84 \\
\hline Garden type $\varangle / \mathbb{Z}$ & 35 & 22 & 0.36 \\
\hline Posterior comminution & 11 & 20 & $<.001 *$ \\
\hline NTS configuration & 22 & 24 & $<.001 *$ \\
\hline $\begin{array}{l}\text { Reduction quality } \\
\text { (moderate/poor) }\end{array}$ & 10 & 17 & $<.001 *$ \\
\hline
\end{tabular}

\section{Univariable and multivariable analysis of risk factors for developing posterior tilt $\left(>5^{\circ}\right)$}

To further identify risk factors for develop posterior tilt, we established a logistic regression model containing posterior comminution, reduction quality, and NTS configuration (reference: ALTS) (Table 3). Firstly, univariable analysis revealed that posterior comminution, reduction quality, and NTS configuration were statistically significant; subsequent multivariable analysis identified posterior comminution (OR $15.9,95 \% \mathrm{Cl} 3.6-70.3, \mathrm{p}<0.001$ ), reduction quality (moderate/poor) (OR 12.0, 95\% Cl 2.6-56.1, $\mathrm{p}=$ 0.002), and NTS configuration (reference: ALTS) (OR 21.9, 95\% Cl 4.1-116.4, $p<0.001$ ) were risk factors for developing posterior tilt.

Table 3

Univariable and multivariable logistic regression analysis of risk factors for developing posterior tilt $\left(>5^{\circ}\right)$

\begin{tabular}{|lllll|}
\hline Variables & \multicolumn{2}{l}{ Univariable analysis } & \multicolumn{2}{l|}{ Multivariable analysis } \\
\cline { 2 - 6 } & OR $(95 \% \mathrm{Cl})$ & $\boldsymbol{p}$ value & OR $(95 \% \mathrm{Cl})$ & $\boldsymbol{p}$ value \\
\hline Posterior comminution & $8.5(3.0-23.8)$ & $<0.001 *$ & $15.9(3.6-70.3)$ & $<0.001$ * \\
\hline Reduction quality (Moderate/poor) & $6.1(2.2-16.7)$ & $<0.001 *$ & $12.0(2.6-56.1)$ & $0.002 *$ \\
\hline NTS configuration & $6.8(2.2-20.5)$ & $0.001 *$ & $21.9(4.1-116.4)$ & $<0.001$ * \\
\hline OR, odds ratio; Cl, confidence interval. & & & & \\
\hline * Statistically significant. & & & & \\
\hline
\end{tabular}




\section{Discussion}

Posterior tilt/posterior neck collapse is frequently encountered after fixation of femoral neck fractures and is associated with further neck shortening and nonunion [14-16]. Additionally, a preoperative posterior tilt of more than $20^{\circ}$ was reported to be a significant predictor for reoperation [11]. It is likely that preoperative posterior tilt of femoral head would largely damage the bony mechanical transduction of the posterior cortex, and the inclination of femoral head retroversion is less likely to be counteracted with the use of normal fixation construct (parallel partially threaded screws), especially in the presence of posterior comminution $[17,18]$. Thus, a more specialized fixation construct is needed to resist posterior tilt in retroverted femoral neck fractures.

Shin et al. [6] recently reported that in the classic configuration of parallel cannulated screws, replacing a partially threaded cannulated screw with a posterior fully threaded positioning screw can prevent femoral neck shortening and posterior tilt in Garden $\nabla$ and $\otimes$ femoral neck fractures, as this hybrid construct was regarded to be more length- and angle-stable, which had already been demonstrated previously by a biomechanical study [19]. Similarly, in our study, the anterior partially threaded compression screw was replaced with a long-threaded positioning screw (Fig. 5), which would also provide length- and anglestability to prevent posterior tilt. Just as was shown in our results, lower increased posterior tilt and smaller amount of FNS were observed in the ALTS group (Table 1). In addition, lateral plating offers better integral property by combining the three screws into a whole one construct. What's more, the screw purchase of the anterior long-threaded screw was larger than that of the other two screws, which was helpful to counteract the tendency of posterior tilt of femoral head.

There might be concerns of inducing nonunion by replacing compression screws with non-sliding positioning screws. However, a study compared short- and long-threaded cancellous screws in the fixation of femoral neck fractures in a randomized trial of 432 patients, and no difference was found regarding fracture healing complications [20]. Thus, we speculate that the absolute length of screw thread may not be determinant in femoral neck fracture fixation. Other factors, including fracture geometry (which largely determines the tendency of fracture displacement), patient characteristics, and reduction quality, may be more important. In this perspective, the strength of our study is that we focused on femoral neck fractures that presented posterior tilt before surgery (in consideration of homogeneity of this study), in whom femoral head retroversion would largely occur postoperatively due to damaged posterior cortical transduction. In this situation, anterior partiality of screw purchase in the ALTS configuration was demonstrated to significantly resist posterior tilt of femoral head. Consequently, we hold the view that in the fixation of femoral neck fractures, implant construct with biomechanical partiality that specifically counteracts the inclination of fracture displacement is of paramount importance to create a balanced mechanical environment for fracture healing (Fig. 5).

Chiang et al. [21] recently reported that three fully threaded headless compression screws, which were normally regarded as a non-sliding length-stable construct, failed to prevent FNS and varus collapse in Garden $\nabla$ and $\otimes$ femoral neck fractures compared with partially threaded screws. We think that though the 
patient population were all non-displaced fractures, the tendency of fracture displacement (in threedimensional orientation) may not be the same due to potential heterogeneity in fracture geometry, bone quality, etc., and thus, the universally used three fully threaded screws may not be effective in all patients. In comparison, the ALTS construct in our study with anterior partiality of screw purchase was used to treat retroverted femoral neck fractures (which was more targeted and specific), and yielded favorable results in terms of decreasing posterior tilt of femoral head. However, precise prediction and evaluation of three-dimensional stability of femoral neck fractures (or inclination of displacement) is still a difficult task, which deserves further study in the future.

FNS was also frequently encountered after fixation of femoral neck fractures. Of note, FNS was reported to be related with length discrepancy of the lower extremity, decreased abductor length, femoral head collapse, hip impingement, and inferior hip function [22-25]. Worse still, femoral neck compaction after surgery has been reported as an important risk factor for avascular necrosis [25]. In our study, the ALTS configuration showed statistically significant difference in decreasing the amount of FNS in the fixation of retroverted femoral neck fractures, one reason may be that by creating a more balanced biomechanical environment, further collapse of femoral neck would be largely hampered. Unfortunately, when using 5 $\mathrm{mm}$ as the cut-off value, the difference was not significant, which implies limited clinical significance. Small sample size and specific study design (anteriorly-partialized screw purchase to resist posterior tilt) may be two explanations for this. Regarding the risk factors for developing posterior tilt of femoral head, we identified posterior comminution as a risk factor, which implies that posterior bony transduction is of vital importance to achieve fracture stability; NTS configuration (in reference to ALTS configuration) was also identified as a risk factor, which proved superiority of the ALTS configuration in resisting femoral head retroversion; also, inferior reduction quality was identified as a risk factor, which was in line with the literature. Altogether, anterior partiality of screw purchase that specifically counteracts the inclination of retroversion and good reduction quality were two important factors for achieving favorable outcomes.

Several limitations existed in this study. First, this retrospective study may contain potential selection bias. Second, the sample size in each group is relatively small. Third, a minimum follow-up of 12 months is relatively short, and long-term complications remain to be evaluated.

\section{Conclusions}

In retroverted femoral neck fractures, anterior positioning screw in proximal femoral plating provides better resistance against femoral head retroversion. In addition, posterior comminution, suboptimal reduction, and NTS configuration (ref: ALTS) are risk factors for developing posterior tilt.

\section{Abbreviations}

ALTS: anterior long-threaded cannulated screw; CCD: caput-collum-diaphysis; Cl: confidence interval; FNS: femoral neck shortening; HHS: Harris Hip Score; NTS: normally short-threaded cannulated screws; OR: odds ratio; SD: standard deviation; THA: total hip arthroplasty. 


\section{Declarations}

\section{Ethics approval and consent to participate}

This study was approved by the Ethic Committee of Shanghai Tenth People's Hospital. The approved No. of ethic committee was SHSY-IEC-4.1/20-198/01. The registration number of this study was ChiCTR2000039482.

\section{Consent for publication}

Written informed consent for publication of their clinical details and/or clinical images was obtained from the patient. A copy of the consent form is available for review by the Editor of this journal.

\section{Availability of data and materials}

The datasets used and/or analyzed during the current study are available from the corresponding author on reasonable request.

\section{Competing interests}

The authors declare that they have no competing interests.

\section{Funding}

This study was funded by National Key R\&D Program of China, grant number 2017YFC0110603; Orthopedic Intelligent Minimally Invasive Diagnosis \& Treatment Center/, Shanghai Tenth People's Hospital, grant number 04.99.18006; and Science and Technology Commission of Shanghai Municipality, grant number 18441901300 .

\section{Authors' contributions}

Zheng LP designed and directed the whole study. Nie SB and Liu JF analyzed and interpreted the patient data, and was two major contributors in writing the manuscript. Zhu JH and Zhou ZF collected and examined the raw data. Zhang $L$ performed literature review and helped to revise the manuscript. All authors read and approved the final manuscript.

\section{Acknowledgements}

Not applicable.

\section{References}

1. Cummings SR, Melton LJ. Epidemiology and outcomes of osteoporotic fractures. Lancet (London, England). 2002;359: 1761-7. 
2. Lee YK, Kim JW, Lee MH, Moon KH, Koo KH. Trend in the Age-Adjusted Incidence of Hip Fractures in South Korea: Systematic Review. Clin Orthop Surg. 2017;9: 420-3.

3. Sjöholm P, Otten V, Wolf O, Gordon M, Karsten G, Sköldenberg O, et al. Posterior and anterior tilt increases the risk of failure after internal fixation of Garden I and II femoral neck fracture. Acta Orthop. 2019;90: 537-41.

4. Okike K, Udogwu UN, Isaac M, Sprague S, Swiontkowski MF, Bhandari M, et al. Not All Garden-I and II Femoral Neck Fractures in the Elderly Should Be Fixed: Effect of Posterior Tilt on Rates of Subsequent Arthroplasty. J Bone Joint Surg Am. 2019;101: 1852-9.

5. Dolatowski FC, Adampour M, Frihagen F, Stavem K, Erik Utvåg S, Hoelsbrekken SE. Preoperative posterior tilt of at least $20^{\circ}$ increased the risk of fixation failure in Garden-I and -II femoral neck fractures. Acta Orthop. 2016;87: 252-6.

6. Shin $\mathrm{KH}$, Hong SH, Han SB. Posterior fully threaded positioning screw prevents femoral neck collapse in Garden I or II femoral neck fractures. Injury. 2020;51: 1031-7.

7. Zhang B, Liu J, Zhu Y, Zhang W. A new configuration of cannulated screw fixation in the treatment of vertical femoral neck fractures. Int Orthop. 2018;42: 1949-55.

8. Park YC, Um KS, Kim DJ, Byun J, Yang KH. Comparison of femoral neck shortening and outcomes between in situ fixation and fixation after reduction for severe valgus-impacted femoral neck fractures. Injury. 2020:

9. Zlowodzki M, Ayeni O, Petrisor BA, Bhandari M. Femoral neck shortening after fracture fixation with multiple cancellous screws: incidence and effect on function. J Trauma. 2008;64: 163-9.

10. Weil YA, Khoury A, Zuaiter I, Safran O, Liebergall M, Mosheiff R. Femoral neck shortening and varus collapse after navigated fixation of intracapsular femoral neck fractures. J Orthop Trauma. 2012;26: 19-23.

11. Palm H, Gosvig K, Krasheninnikoff M, Jacobsen S, Gebuhr P. A new measurement for posterior tilt predicts reoperation in undisplaced femoral neck fractures: 113 consecutive patients treated by internal fixation and followed for 1 year. Acta Orthop. 2009;80: 303-7.

12. Kalsbeek JH, van Walsum ADP, Roerdink WH, van Vugt AB, van de Krol H, Schipper IB. Validation of two methods to measure posterior tilt in femoral neck fractures. Injury. 2020;51: 380-3.

13. Guimarães JAM, Rocha LR, Noronha Rocha TH, Bonfim DC, da Costa RS, Dos Santos Cavalcanti A, et al. Vertical femoral neck fractures in young adults: a closed fixation strategy using a transverse cancellous lag screw. Injury. 2017;48 Suppl 4: S10-s6.

14. Bjørgul K, Reikerås 0 . Outcome of undisplaced and moderately displaced femoral neck fractures. Acta Orthop. 2007;78: 498-504.

15. Conn KS, Parker MJ. Undisplaced intracapsular hip fractures: results of internal fixation in 375 patients. Clin Orthop Relat Res. 2004: 249-54.

16. Scheck M. The significance of posterior comminution in femoral neck fractures. Clin Orthop Relat Res. 1980: 138-42. 
17. Zahid M, Bin Sabir A, Asif N, Julfiqar M, Khan AQ, Ahmad S, et al. Fixation using cannulated screws and fibular strut grafts for fresh femoral neck fractures with posterior comminution. J Orthop Surg (Hong Kong). 2012;20: 191-5.

18. Rawall S, Bali K, Upendra B, Garg B, Yadav CS, Jayaswal A. Displaced femoral neck fractures in the young: significance of posterior comminution and raised intracapsular pressure. Arch Orthop Trauma Surg. 2012;132: 73-9.

19. Schaefer TK, Spross C, Stoffel KK, Yates PJ. Biomechanical properties of a posterior fully threaded positioning screw for cannulated screw fixation of displaced neck of femur fractures. Injury. 2015;46: 2130-3.

20. Parker MJ, Ali SM. Short versus long thread cannulated cancellous screws for intracapsular hip fractures: a randomised trial of 432 patients. Injury. 2010;41: 382-4.

21. Chiang MH, Wang CL, Fu SH, Hung CC, Yang RS. Does fully-threaded Headless Compression Screw provide a length-stable fixation in undisplaced femoral neck fractures? Asian J Surg. 2019;42: 320-5.

22. Gurney B, Mermier C, Robergs R, Gibson A, Rivero D. Effects of limb-length discrepancy on gait economy and lower-extremity muscle activity in older adults. J Bone Joint Surg Am. 2001;83: 907-15.

23. McGrory BJ, Morrey BF, Cahalan TD, An KN, Cabanela ME. Effect of femoral offset on range of motion and abductor muscle strength after total hip arthroplasty. The Journal of bone and joint surgery. British volume. 1995;77: 865-9.

24. Slobogean GP, Stockton DJ, Zeng BF, Wang D, Ma B, Pollak AN. Femoral neck shortening in adult patients under the age of 55 years is associated with worse functional outcomes: Analysis of the prospective multi-center study of hip fracture outcomes in China (SHOC). Injury. 2017;48: 1837-42.

25. Nanty L, Canovas F, Rodriguez T, Faure P, Dagneaux L. Femoral neck shortening after internal fixation of Garden I fractures increases the risk of femoral head collapse. Orthop Traumatol Surg Res. 2019;105: 999-1004.

\section{Figures}



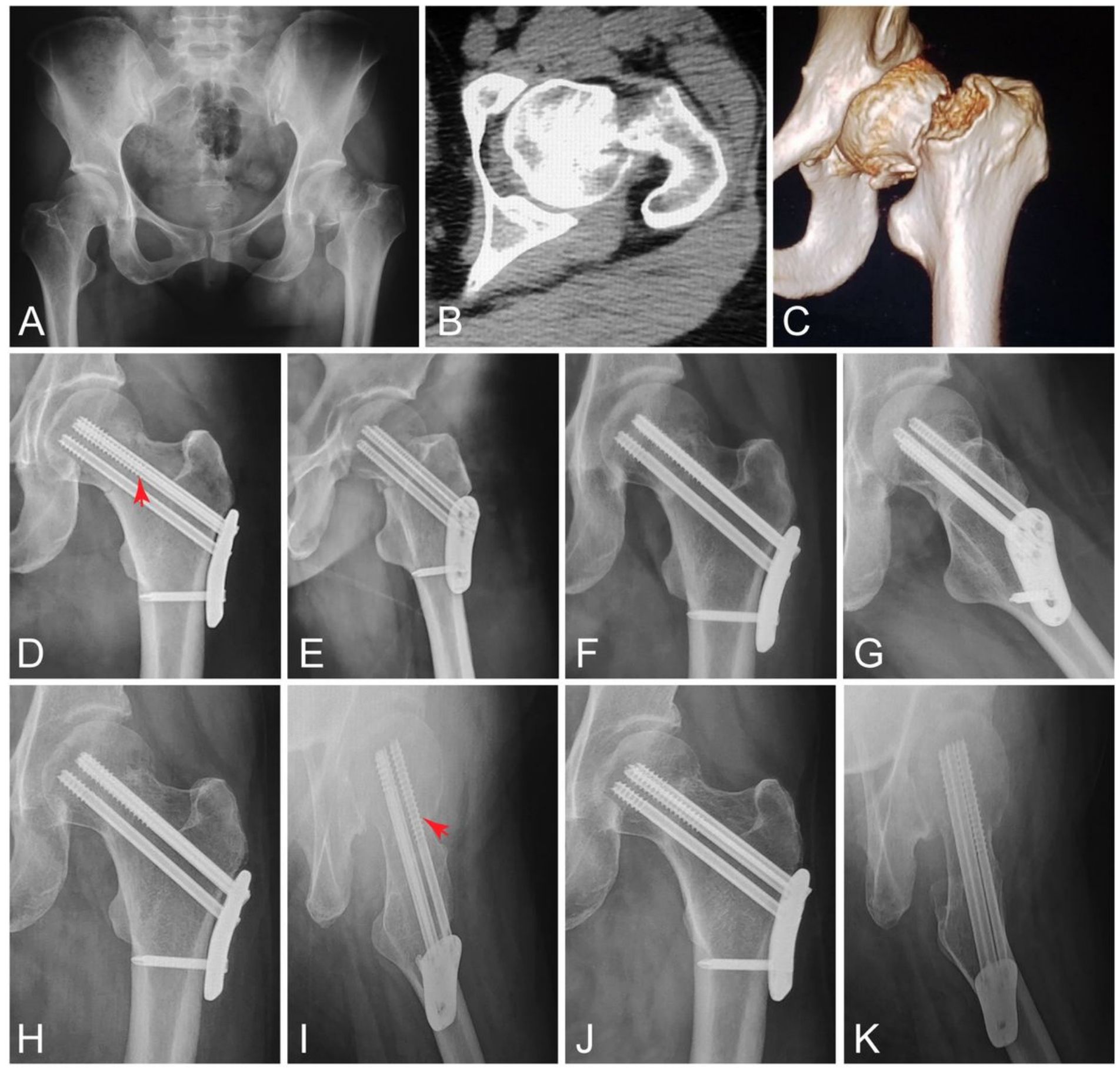

\section{Figure 1}

Proximal femoral plating of a 41-year-old female with retroverted femoral neck fracture (Garden type $\varangle$ ). (A) Preoperative X-ray. (B,C) Preoperative CT-scans and three-dimensional reconstruction. Postoperative radiographs at one day $(\mathrm{D}, \mathrm{E})$ (arrowhead: anterior long-threaded screw), four months $(\mathrm{F}, \mathrm{G})$, six months $(\mathrm{H}, \mathrm{I})$ (arrowhead: anterior long-threaded screw), and 12 months $(\mathrm{J}, \mathrm{K})$ (posterior tilt: $\left.-3.3^{\circ}\right)$. 

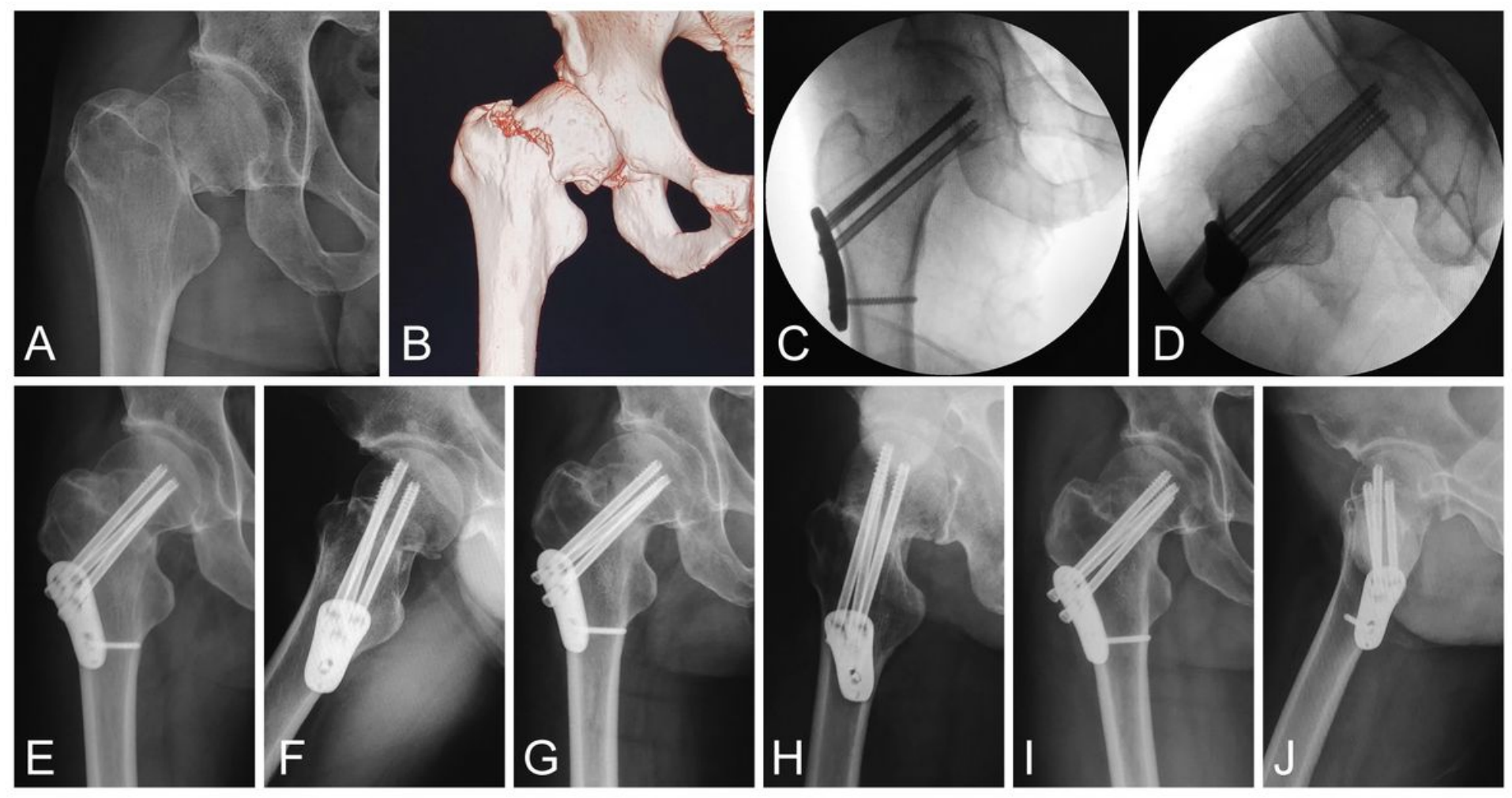

\section{Figure 2}

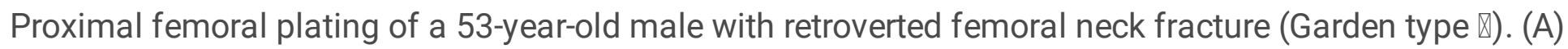
Preoperative X-ray. (B) Three-dimensional reconstruction of CT-scans. (C,D) Intraoperative anteroposterior and lateral radiographs of definitive fixation (posterior tilt: $4.7^{\circ}$ ). Postoperative radiographs at one month (posterior tilt: $\left.11.1^{\circ}\right)(\mathrm{E}, \mathrm{F})$, six months $(\mathrm{G}, \mathrm{H})$, and 12 months $(\mathrm{I}, \mathrm{J})$.
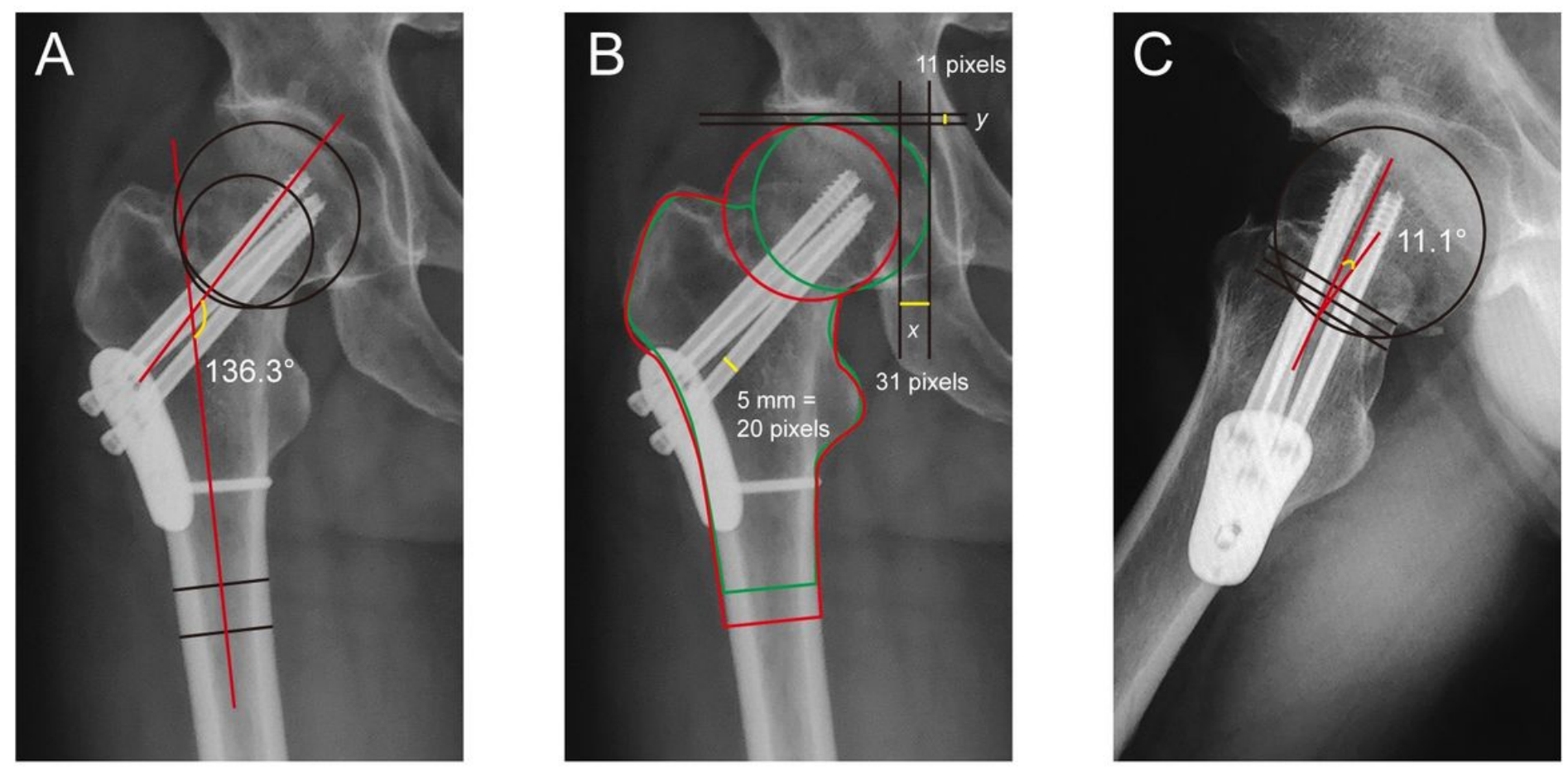

Figure 3 
Measurement of CCD angle (A), amount of femoral neck shortening (B), and posterior tilt angle (C) in femoral neck fractures. CCD, caput-collum-diaphysis.

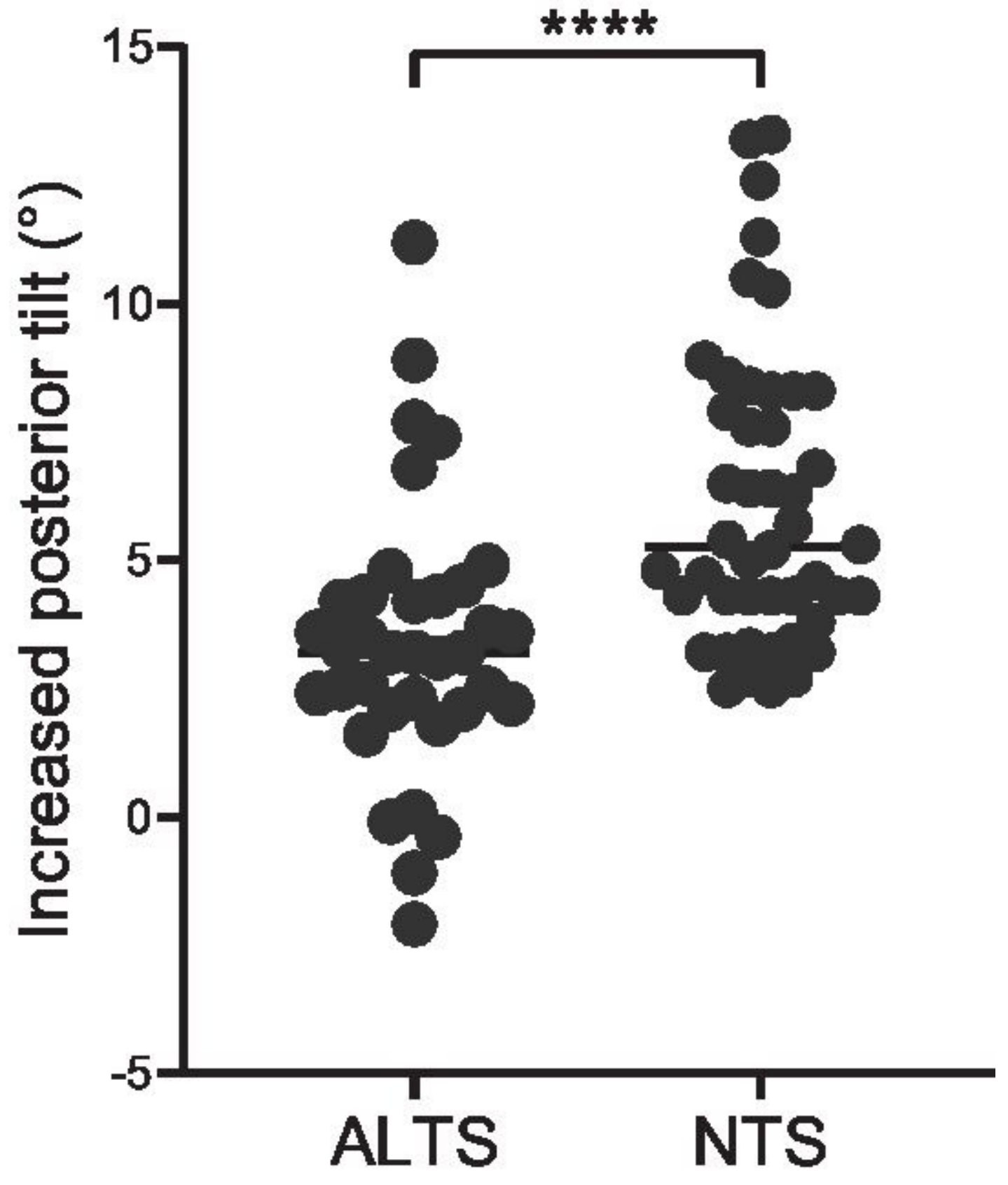

Figure 4

Comparative analysis of increased posterior tilt between the two groups. $* \star \star \star p<0.0001$. ALTS, anterior long-threaded cannulated screw; NTS, normally short-threaded cannulated screws. 

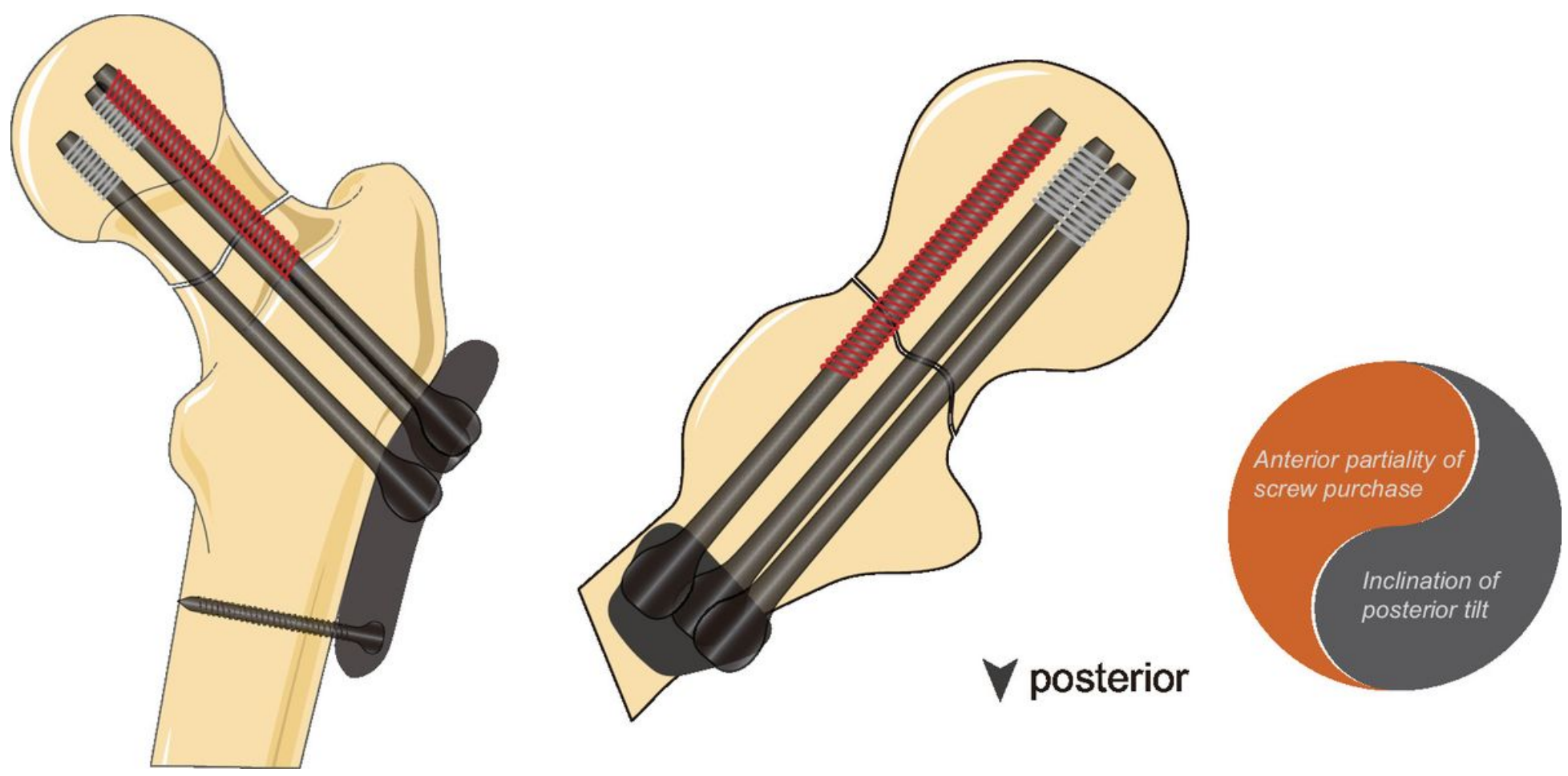

Figure 5

Graphical illustration of proximal femoral plating with an anterior long-threaded cannulated screw in the fixation of retroverted femoral neck fractures. By employing a screw with longer thread in the anterior part of femoral head, which provide greater holding force to avoid malposition, inclination of posterior tilt of the femoral head could be better counteracted. 